\title{
Emerging Asian aerosol patterns
}

Article

Accepted Version

Samset, B. H., Lund, M. T., Bollasina, M. A., Myhre, G. and Wilcox, L. (2019) Emerging Asian aerosol patterns. Nature Geoscience, 12. pp. 582-584. ISSN 1752-0894 doi: https://doi.org/10.1038/s41561-019-0424-5 Available at https://centaur.reading.ac.uk/85063/

It is advisable to refer to the publisher's version if you intend to cite from the work. See Guidance on citing.

To link to this article DOI: http://dx.doi.org/10.1038/s41561-019-0424-5

Publisher: Nature Publishing Group

All outputs in CentAUR are protected by Intellectual Property Rights law, including copyright law. Copyright and IPR is retained by the creators or other copyright holders. Terms and conditions for use of this material are defined in the End User Agreement.

\section{$\underline{\text { www.reading.ac.uk/centaur }}$}

\section{CentAUR}

Central Archive at the University of Reading

Reading's research outputs online 
Emerging Asian aerosol patterns

Bjørn H. Samset ${ }^{1}$, Marianne T. Lund ${ }^{1}$, Massimo Bollasina ${ }^{2}$, Gunnar Myhre ${ }^{1}$, Laura Wilcox ${ }^{3}$

${ }^{1}$ CICERO Center for International Climate Research, Oslo, Norway

${ }^{2}$ School of GeoSciences, Grant Institute, University of Edinburgh, Edinburgh, UK

${ }^{3}$ National Centre for Atmospheric Science, Department of Meteorology, University of

Reading, UK

\section{The climate of South and East Asia is affected by anthropogenic aerosols, but the magnitude of the aerosol imprint is not well known. As regional emissions are rapidly changing, potential related climate risks must be quantified.}

Anthropogenic aerosol emissions over Asia are changing rapidly, both in composition and spatial distribution $^{1,2}$. The Shared Socioeconomic Pathways (SSPs), potential narratives of development used by the Intergovernmental Panel for Climate Change in future projections, span a range of influences of aerosols on climate over the next decades. Several of these narratives project the continuation of a trend manifested in observations since 2010, with a clear dipole between South and East Asia.

The patterns of radiative forcing that result from these distributions of aerosols will differ from those of the late $20^{\text {th }}$ century. They may instigate large-scale atmospheric responses that could have wide ranging impacts on climate and society well beyond the aerosol source regions. South and East Asia are particularly vulnerable to climate change because of strong seasonal variations in precipitation, high average temperature, and very high population density. Therefore, any aerosol impacts on the strength or seasonal variations in monsoon rainfall, freshwater availability, or climate extremes, will incur large societal costs. We urge the scientific community to make definite progress towards understanding and quantifying the impacts of Asian aerosols and to tackle the potentially large regional and hemispheric implications of these emerging trends.

\section{Aerosols affect Asian climate}

The scientific community has long focused on understanding the intricate dynamics of the climate of South and East Asia. With a population of billions, any change in climate may entail significant hazards and risks. Indeed, in its recent report on the impacts of $1.5^{\circ} \mathrm{C}$ global warming, the Intergovernmental Panel on Climate Change (IPCC) highlighted South and East Asia as a region that faces high multi-hazard climate risk over the coming decades ${ }^{3}$.

Extensive amounts of anthropogenic aerosol emissions are currently being emitted in South and East Asia. Long-term climate variations over South and East Asia since the mid-twentieth century have been substantially modulated by anthropogenic aerosols, of both local and remote origin. Their imprint could have been even larger than what can be ascribed to the globally rising concentrations of greenhouse gases ${ }^{4,5}$. Aerosol cooling in the region as a whole may have masked up to $1{ }^{\circ} \mathrm{C}$ of greenhouse-gas induced surface warming since the preindustrial era in this region. Likewise, the expected twentieth century increase in summer monsoon precipitation from greenhouse gases could have been into a local reduction, as a result of aerosol emissions ${ }^{6}$. Aerosols additionally modulate subseasonal monsoon variability, such as its onset and intraseasonal oscillations ${ }^{7}$; moreover, extreme precipitation rates have been found to be more sensitive to changes in aerosol emissions than to greenhouse gas forcing ${ }^{6,8}$. 


\section{Emerging patterns}

South and East Asian aerosol emissions have been changing rapidly since about 2010, as a result of stringent air quality measures driven by concerns for public health. These measures have led to a rapid reduction in Chinese emissions of $\mathrm{SO}_{2}{ }^{1}$ and other pollutants ${ }^{9}$. This change is readily evident in observations (Figure 1a) as an emerging dipole pattern in total aerosol optical depth: a marked reduction over China, with concurrent increase over India.

How this trend evolves will depend strongly on measures to improve regional air quality and to bring about a transition of the energy system ${ }^{10}$. Whereas an overall reduction in aerosol loading is anticipated, near-term trends in emissions of black carbon and sulfur dioxide $\left(\mathrm{SO}_{2}\right)$ differ over China and India between the main scenarios. In the following we focus on these two key aerosol species, which have markedly different climate interactions, although simultaneous changes in other species such as ammonium-nitrate and organic carbon will also contribute to determining the total aerosol load. Projected emissions lead to further, strikingly different future patterns of aerosol optical depth changes, as seen in Figure 1b.

Here, present-day emissions based on the Community Emission Data System (CEDS) ${ }^{11}$ and emissions under the Shared Socioeconomic Pathways SSP1-1.9. SSP2-4.5 and SSP3-7.010 were used as input to the atmospheric chemical transport model OsloCTM $3^{12}$. We ran a baseline simulation with Community Emission Data System (CEDS) emissions for the year 2014, and another simulation for each SSP where black carbon and $\mathrm{SO}_{2}$ emissions are taken from year 2030 over South and East Asia but kept at 2014 levels for the rest of the world. The change from 2014 to 2030 change is shown in Figure 1b (Supplementary Figure S1 shows the difference between 2030 and 2050).

For the coming decade, SSP1, which assumes strong air quality policy, projects a strong reduction over the two regions in the aerosol optical depth of both sulfate $\left(\mathrm{SO}_{4}\right)$ and black carbon. SSP2, with medium-strength air quality policy, however, projects increases over India but decreases over China, reminiscent of the recent observed pattern shown in Figure 1a. In fact, more of this dipole may have been realized already than suggested by the model as the decline in Chinese $\mathrm{SO}_{2}$ emissions is weaker in the Community Emission Data System than other studies ${ }^{1,11}$, indicating an underestimate of the impact of China's recent clean air actions. SSP3, standing for weak air quality policy, projects an increase in black carbon aerosol optical depth over both China and India, but with a dipole pattern in sulfate aerosol optical depth change similar to SSP2.

\section{Uncertain implications}

The differences in aerosol loading patterns are clear, but their climate implications are not. The multi-faceted Asian climate, controlled by a variety of atmosphere-ocean-land processes coupled across a wide range of spatial and temporal scales, combined with the limitations of current climate models, make it challenging to predict the implications of such emerging patterns of climate forcing. The picture is further complicated by the complexity of aerosol climate interactions in general. Sulfate produced from industrial $\mathrm{SO}_{2}$ emissions generally cools the climate through scattering of incoming sunlight and by altering cloud properties, whereas black carbon from incomplete combustion processes generally warms through strong absorption of shortwave radiation. Regional feedback processes and mechanisms may further act to partially mask the aerosol signal through compensating changes in other variables ${ }^{13}$. 
After atmospheric transport, emission changes are often linked to climate impacts through a calculation of radiative forcing. However, imperfect knowledge of processes such as aerosolcloud interactions ${ }^{4}$, rapid adjustments ${ }^{14}$ and aerosol optical and microphysical properties ${ }^{15}$ precludes precise quantification of Asian aerosol-induced radiative forcing. As an estimate, however, we show in Figure 1c a calculation of the seasonally-resolved radiative forcing for the two aerosol species and averaged over India and China, resulting from the emission changes in the Shared Socioeconomic Pathways. The estimates are derived by combining the simulations in Figure $1 \mathrm{~b}$ with a radiative kernel $^{16}$, with averaged forcing scaled to the multimodel mean derived in the model intercomparison project AeroCom Phase $\mathrm{II}^{17}$. We scaled the black carbon forcing down by $10 \%$ to account for rapid adjustments, based on a multi-model study $^{14}$, and the sulfate forcing up by $100 \%$ to account for aerosol-cloud interaction effects on cloud albedo and lifetime. The latter is based on estimates from the Fifth assessment report from the IPCC $(\mathrm{AR} 5)^{18}$, and a separate, multi-model investigation ${ }^{2}$. Such scaling is an oversimplification and carries significant uncertainty, but is nevertheless representative of present knowledge.

Figure 1c shows how a dipole pattern in emissions and aerosol loading may carry over to radiative forcing, albeit modulated by the generally opposing forcing from black carbon and $\mathrm{SO}_{4}$ when taken at top-of-atmosphere. For SSP1, we find a strongly seasonal pattern in radiative forcing for the period 2014 to 2030, over both regions, whereas for SSP2 and SSP3 the radiative forcing is generally negative over India but positive over China. The radiative forcing between 2030 and 2050 (Figure S1) is weaker than for the first decade, but still ranges between $\pm 1 \mathrm{Wm}^{-2}$ averaged over the whole region.

Note, however, that even a balance between $\mathrm{SO}_{4}$ and black carbon forcing at the top of the atmosphere may cause marked changes to regional climate, as they have physically distinct climate interactions. Notably, black carbon induces significant shortwave heating through the atmospheric column, hypothesized to have an impact on monsoon patterns, and shown to strongly suppress precipitation in climate models ${ }^{19}$. Black carbon also affects surface albedo through accumulation on snow ${ }^{20}$.

Generally, the climate responses to aerosol loading and forcing patterns such those shown in Figure 1 are highly uncertain. They must be calculated through coupled climate models, but these models have known and persistent biases, for example, in their representation of clouds and wind patterns ${ }^{21}$. Their simulated response of the monsoons to aerosol perturbations is under debate ${ }^{22,23}$, as are their representation of precipitation and temperature extremes ${ }^{24,25}$.

\section{Risks and opportunities}

Behind these uncertainties lie potential impacts on a large number of people. Over the coming years and decades, the forcing resulting from rapid, inter-regional changes like those projected in the SSPs may induce very noticeable effects on regional Asian climate, and beyond. Potential impacts include changes to mean and extreme temperature and precipitation, the onset and strength of the monsoon systems, freshwater availability and changes to air quality. The high societal risks make a compelling case for the science community to step up synergistic efforts to tackle the challenges noted above.

Figure 1d lists some key uncertainties that remain before we can rigorously link Asian aerosol emission changes to local or remote impacts on society. Several ongoing community efforts, 
such as PDRMIP ${ }^{19}$, DAMIP ${ }^{26}$, AerChemMIP ${ }^{27}$ and the harmonization of historical emission inventories with the SSP scenarios ${ }^{28}$, are already poised to tackle the issues raised by the coming changes. However, given the strong likelihood of nonlinear interactions between the responses to Indian and Chinese aerosol, our understanding of past change may not be enough to give us a good understanding of the future climate in this region. We highlight three key challenges and opportunities that may be readily addressed by the community:

Emission inventories: Existing time series must be continuously updated and harmonized with the best available observations and national statistics, including regional trends for black carbon, $\mathrm{SO}_{2}$ and other aerosol species and precursors separately. Further development of high spatial resolution emission inventories is also needed ${ }^{29}$. In parallel, we urge the community to utilize the full range of SSPs when studying climate impacts in South and East Asia, as a much broader range of global and regional developments is spanned than in scenarios of the previous generation. We recommend even to consider extending emission scenarios beyond the envelope of SSP projections.

Observable evolution: The contrasting emission changes that will likely play out over the coming decades offer unique opportunities for improved process understanding - if accompanied by a ramp-up in observations, analogous to the use of field measurements from volcanic eruptions to constrain the aerosol-cloud response ${ }^{30}$. Coordinated and continuous measurements of a broad range of variables, in open and accessible databases, may provide a key to further unravel the mysteries of the aerosol-climate interaction.

Integrated approaches: Delineating the dynamical responses to inter-regional patterns of cooling and warming (including heating from black carbon aloft), with particular focus on aerosol-cloud interactions, monsoons, and changes to extreme precipitation, drought, and internal variability, requires combining state-of-the-art models, improved physical understanding, and observations. With the driving mechanisms spanning and interacting across a wide range of spatiotemporal scales, a hierarchy of modeling tools is needed. This calls for a closer integration, and continuation, of ongoing efforts within the climate dynamics and aerosol modeling communities.

India and China have both been noted as countries facing high levels of climate-related multihazards, regardless of the level of future air quality measures ${ }^{3}$. Even if the probability of strong aerosol effects is low, the impacts could be significant when co-evolving with greenhouse gas concentrations and global warming. It will therefore be prudent to put every effort into unraveling the complex physical interactions between aerosols and Asian climate. 
Figure
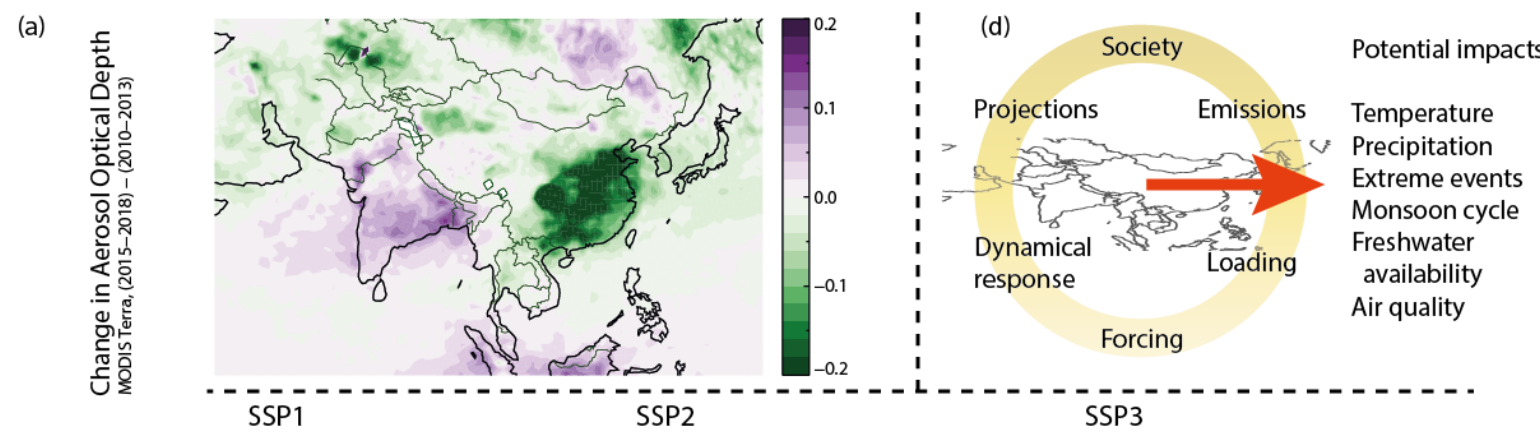

(b)

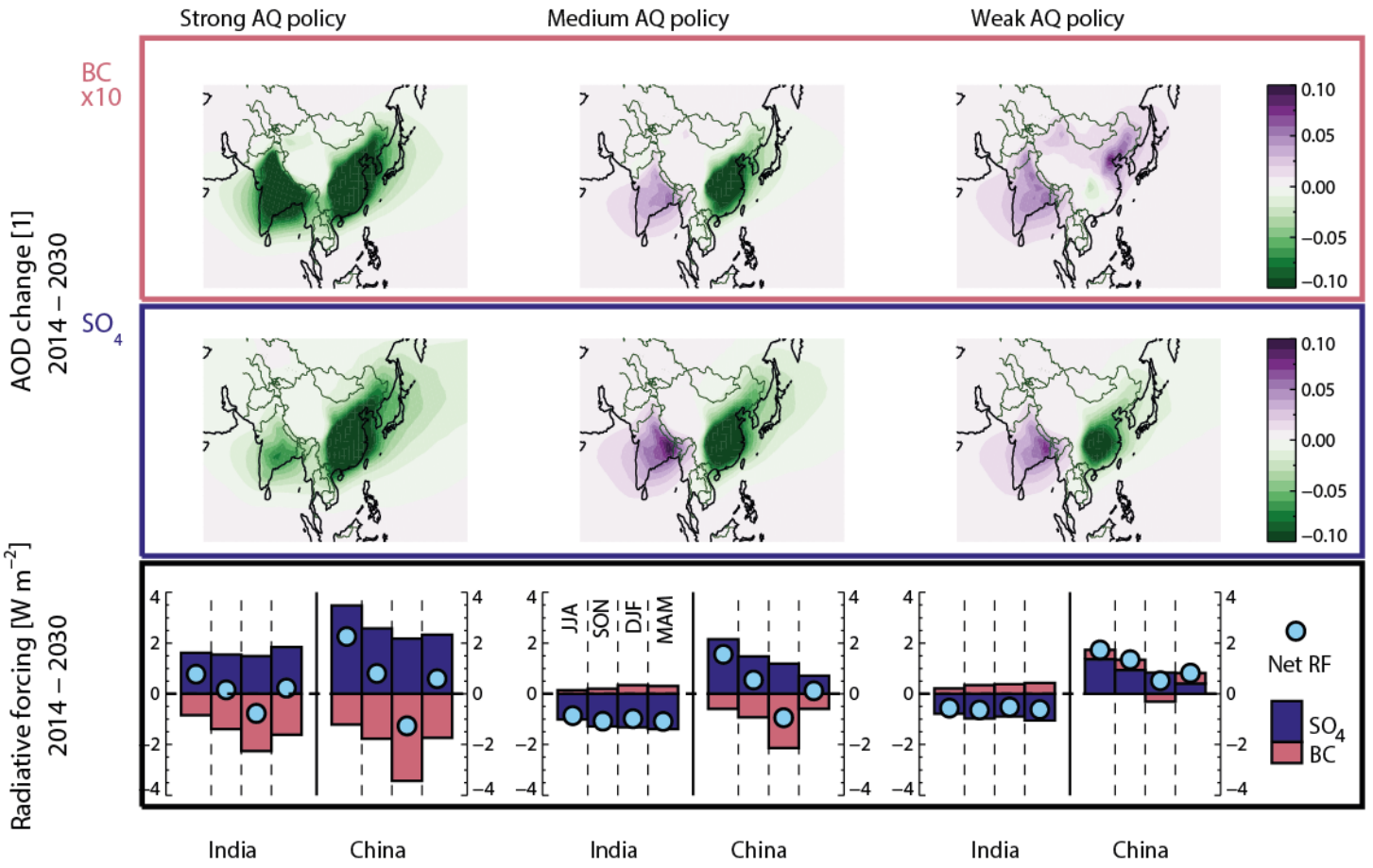

Figure 1: Recent and expected emissions changes lead to striking patterns of change in aerosol loading and radiative forcing over South and East Asia, as already seen by MODIS Terra since 2010 (a). The Shared Socioeconomic Pathways project continued changes (b), here for black carbon and sulfate $\left(\mathrm{SO}_{4}\right)$, depending on the assumptions made about regional air quality policy. SSP1 (left) assumes strong policies, SSP2 medium and SSP3 (right) weak policies. These changes will lead to a net regional aerosol radiative forcing (c; blue circles) that is seasonally dependent, and balance between reduced warming from absorbing black carbon (red) and reduced cooling from $\mathrm{SO}_{4}$ (blue) from direct scattering and modification of clouds. Aerosol emissions are integrally linked to society through transport, industry, health and other factors, and changes to the circle of causes and effects may alter the risks of a range of climate related impacts (d). 


\section{References}

1 Li, C. et al. India Is Overtaking China as the World's Largest Emitter of Anthropogenic Sulfur Dioxide. Sci Rep 7, 14304, doi:10.1038/s41598-017-14639-8 (2017).

2 Myhre, G. et al. Multi-model simulations of aerosol and ozone radiative forcing due to anthropogenic emission changes during the period 1990\&amp;ndash;2015.

Atmospheric Chemistry and Physics 17, 2709-2720, doi:10.5194/acp-17-2709-2017 (2017).

3 O. Hoegh-Guldberg et al. Impacts of $1.5^{\circ} \mathrm{C}$ global warming on natural and human systems. In: Global warming of $1.5^{\circ} \mathrm{C}$. An IPCC Special Report on the impacts of global warming of $1.5^{\circ} \mathrm{C}$ above pre-industrial levels and related global greenhouse gas emission pathways, in the context of strengthening the global response to the threat of climate change, sustainable development, and efforts to eradicate poverty [V. MassonDelmotte, P. Zhai, H. O. Pörtner, D. Roberts, J. Skea, P.R. Shukla, A. Pirani, W. Moufouma-Okia, C. Péan, R. Pidcock, S. Connors, J. B. R. Matthews, Y. Chen, X. Zhou, M. I. Gomis, E. Lonnoy, T. Maycock, M. Tignor, T. Waterfield (eds.)]. In Press. (2018).

$4 \mathrm{Li}, \mathrm{Z}$. et al. Aerosol and monsoon climate interactions over Asia. Reviews of Geophysics 54, 866-929, doi:10.1002/2015rg000500 (2016).

5 Lau, W. K. M. The aerosol-monsoon climate system of Asia: A new paradigm. Journal of Meteorological Research 30, 1-11, doi:10.1007/s13351-015-5999-1 (2016).

6 Samset, B. H. et al. Climate Impacts From a Removal of Anthropogenic Aerosol Emissions. Geophysical Research Letters 45, 1020-1029, doi:10.1002/2017g1076079 (2018).

7 Kitoh, A. The Asian Monsoon and its Future Change in Climate Models: A Review. Journal of the Meteorological Society of Japan. Ser. II 95, 7-33, doi:10.2151/jmsj.2017-002 (2017).

8 Wang, Z. et al. Scenario dependence of future changes in climate extremes under 1.5 degrees C and 2 degrees C global warming. Sci Rep 7, 46432, doi:10.1038/srep46432 (2017).

9 Zheng, B. et al. Trends in China's anthropogenic emissions since 2010 as the consequence of clean air actions. Atmospheric Chemistry and Physics 18, 1409514111, doi:10.5194/acp-18-14095-2018 (2018).

10 Rao, S. et al. Future air pollution in the Shared Socio-economic Pathways. Global Environmental Change 42, 346-358, doi:10.1016/j.gloenvcha.2016.05.012 (2017).

11 Hoesly, R. M. et al. Historical (1750-2014) anthropogenic emissions of reactive gases and aerosols from the Community Emissions Data System (CEDS). Geoscientific Model Development 11, 369-408, doi:10.5194/gmd-11-369-2018 (2018).

12 Lund, M. T. et al. Concentrations and radiative forcing of anthropogenic aerosols from 1750 to 2014 simulated with the Oslo CTM3 and CEDS emission inventory. Geoscientific Model Development 11, 4909-4931, doi:10.5194/gmd-11-4909-2018 (2018).

13 Storelvmo, T. et al. Lethargic Response to Aerosol Emissions in Current Climate Models. Geophysical Research Letters 45, 9814-9823, doi:10.1029/2018gl078298 (2018).

14 Stjern, C. W. et al. Rapid Adjustments Cause Weak Surface Temperature Response to Increased Black Carbon Concentrations. Journal of Geophysical Research:

Atmospheres 122, 11,462-411,481, doi:10.1002/2017jd027326 (2017). 
15 Peng, J. et al. Markedly enhanced absorption and direct radiative forcing of black carbon under polluted urban environments. Proceedings of the National Academy of Sciences 113, 4266-4271, doi:10.1073/pnas.1602310113 (2016).

16 Samset, B. H. \& Myhre, G. Vertical dependence of black carbon, sulphate and biomass burning aerosol radiative forcing. Geophysical Research Letters 38, n/a-n/a, doi:10.1029/2011gl049697 (2011).

17 Myhre, G. et al. Radiative forcing of the direct aerosol effect from AeroCom Phase II simulations. Atmospheric Chemistry and Physics 13, 1853-1877, doi:DOI 10.5194/acp-13-1853-2013 (2013).

18 Boucher, O. et al. Clouds and Aerosols. In: Climate Change 2013: The Physical Science Basis. Contribution of Working Group I to the Fifth Assessment Report of the Intergovernmental Panel on Climate Change [Stocker, T.F., D. Qin, G.-K. Plattner, M. Tignor, S.K. Allen, J. Boschung, A. Nauels, Y. Xia, V. Bex and P.M. Midgley (eds.)]. Cambridge University Press, Cambridge, United Kingdom and New York, NY, USA. (2013).

19 Samset, B. H. et al. Fast and slow precipitation responses to individual climate forcers: A PDRMIP multimodel study. Geophysical Research Letters 43, 2782-2791, doi:10.1002/2016GL068064 (2016).

20 Yasunari, T. J., Koster, R. D., Lau, W. K. M. \& Kim, K.-M. Impact of snow darkening via dust, black carbon, and organic carbon on boreal spring climate in the Earth system. Journal of Geophysical Research: Atmospheres 120, 5485-5503, doi:10.1002/2014jd022977 (2015).

21 Wilcox, L. J., Dong, B., Sutton, R. T. \& Highwood, E. J. The 2014 Hot, Dry Summer in Northeast Asia. Bulletin of the American Meteorological Society 96, S105-S110, doi:10.1175/bams-d-15-00123.1 (2015).

22 Bartlett, R. E. et al. Do differences in future sulfate emission pathways matter for near-term climate? A case study for the Asian monsoon. Climate Dynamics, doi:10.1007/s00382-017-3726-6 (2017).

23 Krishnan, R. et al. Deciphering the desiccation trend of the South Asian monsoon hydroclimate in a warming world. Climate Dynamics 47, 1007-1027, doi:10.1007/s00382-015-2886-5 (2015).

24 Zhao, A. D., Stevenson, D. S. \& Bollasina, M. A. The role of anthropogenic aerosols in future precipitation extremes over the Asian Monsoon Region. Climate Dynamics, doi:10.1007/s00382-018-4514-7 (2018).

25 Lin, L. et al. Changes in Extreme Rainfall Over India and China Attributed to Regional Aerosol-Cloud Interaction During the Late 20th Century Rapid Industrialization. Geophysical Research Letters 45, 7857-7865, doi:10.1029/2018g1078308 (2018).

26 Gillett, N. P. et al. The Detection and Attribution Model Intercomparison Project (DAMIP v1.0)

contribution to CMIP6. Geoscientific Model Development 9, 3685-3697, doi:10.5194/gmd-93685-2016 (2016).

27 Collins, W. J. et al. AerChemMIP: quantifying the effects of chemistry and aerosols in CMIP6. Geoscientific Model Development 10, 585-607, doi:10.5194/gmd-10-5852017 (2017).

28 Gidden, M. J. et al. Global emissions pathways under different socioeconomic scenarios for use in CMIP6: a dataset of harmonized emissions trajectories through the end of the century. Geoscientific Model Development 12, 1443-1475, doi:10.5194/gmd-12-1443-2019 (2019). 
29 Wang, R. et al. Estimation of global black carbon direct radiative forcing and its uncertainty constrained by observations. Journal of Geophysical Research: Atmospheres 121, 5948-5971, doi:10.1002/2015JD024326 (2016).

30 Malavelle, F. F. et al. Strong constraints on aerosol-cloud interactions from volcanic eruptions. Nature 546, 485-491, doi:10.1038/nature22974 (2017). 
Supplementary Material

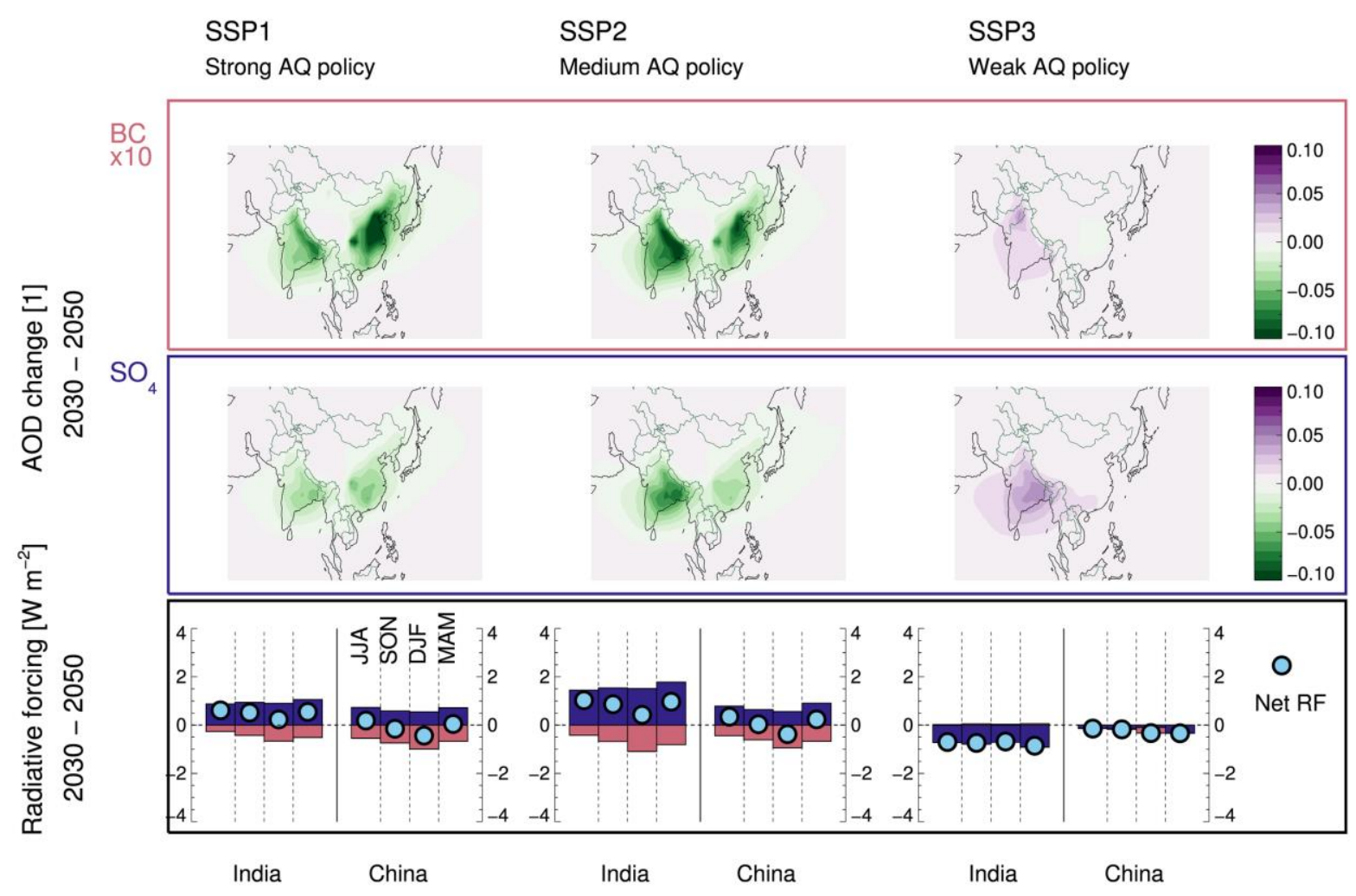

Figure S1: As Figure 1, for 2030-2050. 